RIVERA ANDÍA Juan Javier (ed.), Comprender los rituales ganaderos en los Andes y más allá. Etnografías de lidias, herranzas y arrierías

Aachen, Shaker Verlag (Bonner amerikanistische Studien, 51), 2014, 500 p., ill. en coul., mapas.

Francisco Pazzarelli

\title{
CpenEdition
}

Journals

Edición electrónica

URL: https://journals.openedition.org/jsa/14708

DOI: $10.4000 /$ jsa. 14708

ISSN: $1957-7842$

Editor

Société des américanistes

Edición impresa

Fecha de publicación: 31 octubre 2016

Paginación: 197-201

ISSN: 0037-9174

Referencia electrónica

Francisco Pazzarelli, «RIVERA Andía Juan Javier (ed.), Comprender los rituales ganaderos en los Andes y más allá. Etnografías de lidias, herranzas y arrierías», Journal de la Société des américanistes [En línea], 102-1 | 2016, Publicado el 05 diciembre 2016, consultado el 03 septiembre 2022. URL: http:// journals.openedition.org/jsa/14708 ; DOI: https://doi.org/10.4000/jsa.14708

Este documento fue generado automáticamente el 3 septiembre 2022.

All rights reserved 


\section{RIVERA ANDÍA Juan Javier (ed.), Comprender los rituales ganaderos en los Andes y más allá. Etnografías de lidias, herranzas y arrierías}

Aachen, Shaker Verlag (Bonner amerikanistische Studien, 51), 2014, 500 p., ill. en coul., mapas.

\section{Francisco Pazzarelli}

\section{REFERENCIA}

RIVERA ANDÍA Juan Javier (ed.), Comprender los rituales ganaderos en los Andes y más allá.

Etnografías de lidias, herranzas y arrierías, Aachen, Shaker Verlag (Bonner amerikanistische Studien, 51), 2014, 500 p., ill. en coul., mapas.

1 Como lo señala Peter Gose en su prefacio, a pesar de siglos de «mestizajes » y de la incorporación de especies animales europeas a las economías andinas, los llamados « rituales ganaderos» siguen allí, entre los cerros. Sea porque forman parte de un impulso «estructural» imposible de esquivar (como sugiere Gose, p.10), porque constituyen un « comentario » de conceptos caros a las lógicas andinas (como propone el compilador, p.64), o bien porque son parte indispensable de su «aparato tecno(cosmo)lógico » (como apunta Bugallo, p.311), los rituales ganaderos se multiplican por buena parte de la geografía andina (y más allá). Este libro, de doce artículos y una introducción, constituye una buena entrada para cualquier lector interesado en ellos y en descubrir la fuerza con la cual unen los pastores, sus ganados y su entorno.

2 La introducción de Juan Javier Rivera Andía presenta una propuesta general para el análisis de los rituales ganaderos andinos - el de la herranza especialmente - que destaca dos aspectos muy importantes de sus efectos relacionales. En primer lugar, hombres y 
animales, inicialmente reunidos e identificados, son luego separados y marcados como diferentes. Estos momentos de « conjunción 》 y « disyunción » poseen paralelismos con los diferentes tipos de "maduraciones» y el consecuente "paso» de hombres y animales al terreno de lo social. En segundo lugar, la relación de los pastores con sus animales incluye siempre la mediación de un tercer término: los cerros. Los animales criados son inicialmente dones recibidos de los cerros para luego volverse dones que se ofrecen a ellos. El ritual se encargaría así, según la tesis del autor, de transformar la crianza de animales en un ofrecimiento, marcando los términos de una " alianza » entre los pastores y los cerros, la cual sería mantenida mediante diferentes y reiterados " pagos ». La referencia a la alianza coloca al parentesco como una llave indispensable para abordar estas relaciones ${ }^{1}$, lo cual tiene resonancias en todos los capítulos que siguen.

La primera parte de la compilación, «Etnografías del centro y sur del Perú », presenta una serie de siete trabajos que recorren distintas fiestas y rituales. Los dos primeros se ocupan de ofrecer descripciones detalladas de eventos en comunidades quechuas del departamento de Puno: Luis Murgía presenta las fiestas taurinas, mientras que Efraín Cáceres Chalco hace lo mismo con los rituales de uywa señalakuy dedicados a la marcación de vacas, ovejas y camélidos. El texto de Enrique Rivera Vela continúa con el recorrido por comunidades de Puno, ya en la frontera con Moquegua, describiendo los ch'allaku, rituales aimaras destinados a las alpacas. Axel Schäfer se ocupa de las relaciones con el ganado vacuno, ovino y caballar en el departamento Apurímac, a través de la descripción de las tinkasqa (rituales de ganado) y de la fiesta de San Santiago. En el mismo departamento, el artículo de Alejandra Ttito Tica pone en relación diferentes conversaciones con pastores sobre los tipos de rituales dedicados a sus rebaños. Ya en el departamento de Ayacucho, Leonor Muñoz Palomino presenta una descripción del qicwariy, viajes de los llameros a las tierras bajas, y del llamatumachiy, ritual dedicado a las llamas macho que retornan de la travesía. El último texto de esta serie, firmado por Máximo Cama Tito, trata la marcación de ganado vacuno en el Cerro de Pasco. En los trabajos que componen esta primera parte el énfasis se encuentra en la descripción de los diferentes momentos del proceso ritual y festivo. Estas contribuciones, ante todo etnográficas, proveen de un corpus muy importante para los interesados en encarar análisis comparativos, como aquellos que se incluyen en los capítulos que siguen.

La segunda parte del libro, « Otras áreas, otros ritos. Elementos comparativos », presenta una serie de cuatro trabajos dedicados a descripciones etnográficas y análisis más arriesgados. Los primeros dos artículos, además, se encuentran en relación directa con las descripciones de contextos andinos desarrolladas en la primera parte. El texto de Rivera Andía propone un análisis comparativo entre los rituales de herranza de animales y la champería o limpieza de acequias, por un lado, y los de inauguración de nuevas casas o zafa-casa, por otro. Comparando sus materiales etnográficos con el de otras regiones, discute la hipótesis ya mencionada que considera a estos eventos como rituales de paso, en los cuales se ponen en juego los ciclos vitales de los protagonistas. El siguiente capítulo, que cierra el recorrido andino del libro, es el de Lucila Bugallo y se ocupa de las concepciones puneñas del multiplico en el Noroeste Argentino. Desde una perspectiva que integra diferentes dimensiones etnográficas, especialmente las " productivas », la autora da cuenta del amplio campo semántico que se incluye en los rituales de Señaladas, donde las relaciones de fertilidad y reproducción se conjugan en las formas específicas que adopta el multiplico de los animales. Los últimos dos trabajos de esta segunda parte continúan explorando el universo animal aunque ya dentro del área mesoamericana. El 
texto de Frédéric Saumade presenta un análisis etnohistórico y etnográfico que discute las formas que la ganadería y la tauromaquia adoptaron en México y el oeste estadounidense. Retomando esta perspectiva, el capítulo presentado por Saumade y Ana Valenzuela-Zapata analiza las relaciones entre las lógicas amerindias que incluían al venado, la introducción de animales europeos (caballos y vacas) y el uso de plantas (agaves) para la fabricación de cuerdas y reatas de rodeos. Ambos capítulos sostienen que las formas que adoptaron la ganadería y la tauromaquia se vinculan con las articulaciones lógicas entre los universos indígenas e hispanos, que no se reducen a una imposición del polo europeo sobre el americano. La compilación termina con un Glosario con todos los términos específicos utilizados.

5 En términos generales, un aspecto que debe destacarse en todos los trabajos es la riqueza etnográfica. Cada evento es desmenuzado en todos sus detalles, considerando los distintos momentos del proceso ritual y revelando las diferencias en el tratamiento de cada uno de los animales. Los diferentes capítulos traen a la discusión, incluso, una serie de datos que no siempre se encuentran disponibles: las recetas de las comidas preparadas y consumidas durante los rituales, la construcción de las estructuras necesarias para los mismos o bien las formas en las que se ejecutan los sacrificios y desuelles de los animales. Al mismo tiempo, los análisis no se detienen en clasificaciones previas (ni simplistas) sobre la naturaleza más o menos indígena (o andina) de los animales protagonistas: llamas y alpacas pueblan las descripciones tanto como lo hacen las ovejas, vacas, caballos, toros y cabras. En este sentido, lo que esta compilación consigue mostrar a través de la diversidad de sus descripciones es la imposibilidad de suturar la compresión de los rituales ganaderos en los términos de una explicación totalizadora o reduccionista. No obstante, los diferentes capítulos sugieren algunas líneas de investigación que podrían ayudar a profundizar los estudios comparativos.

6 Por un lado, tenemos la propuesta de análisis que se presenta en la Introducción y que es luego completada en el artículo del propio Rivera Andía, a través de las comparaciones etnográficas ya mencionadas. El diálogo entre esta propuesta y el resto de los trabajos, sin embargo, es menos explícito y el establecimiento de estas relaciones (o incluso sus modulaciones locales) queda a cargo del lector. En cambio, es la alusión inicial al parentesco como llave relacional la que sigue presente como una suerte de implícito hilo conductor. Se trata de aquella certeza, expresada con diferentes voces y tenores en los distintos capítulos, de que los animales de crianza no son sólo « animales » y de que es imposible pensarlos como meros objetos o reservorios de carne. Una idea de este tipo se derrumba ante cualquiera de las decenas de situaciones que describen el « cariño » con el que se trata a los rebaños: la alegría de los criadores que reciben a sus animales para el siñalakuy (referida por Cáceres Chalco, p. 138), la contundencia de las palabras de una pastora ayacuchana al hablar de sus alpacas ( ¿ ¿ómo una madre no va a reconocer a sus hijos e hijas? », en el texto de Muñoz Palomino, p. 241) o los hombres transformados en toros durante las fiestas (como apunta Schäfer, p. 212), entre otras. Estos ejemplos no sólo revelan la relación íntima entre hombres y animales, sino que cuestionan el concepto mismo de « animal » en los Andes. Llamas, ovejas y vacas se presentan como miembros, tan inestables como cualquier otro, de redes de relaciones familiares que no siempre consiguen separar con precisión aquello que sería humano de aquello que no.

7 Ese « cariño » para con los animales, no obstante, no constituye ni un adjetivo romántico ni una alusión metafórica. Refiere, en cambio, a la lógica de aquellas relaciones que para algunos autores de este libro (Bugallo, por ejemplo) podrían definirse como « crianzas 
mutuas ». Esta relación hace tambalear el concepto moderno de "domesticación » y se desdobla hacia distintas direcciones, incorporando (y podríamos decir fabricando) diferentes tipos de agentes, con distintos niveles de inclusión. El bello ejemplo de Bugallo, acerca de cómo las llamas « pagan » con sus flores de lana el pasto que comen del cerro (p. 337-338), es una invitación a pensar sobre esta aparente « cualidad fractal » de las relaciones de crianza. Una cualidad que dificulta imaginar que la posición de pastor o criador (o de criado) pueda ser sólo ocupada por humanos (o animales) y ejecutada únicamente en una dirección (Martínez 1989). O incluso si esa misma posición podría ser constituida de forma "individual ", o debería tal vez ser abordada en los términos de un agenciamiento colectivo. En este sentido, y apelando a la voluntad comparativa de la compilación, restaría saber si las lógicas de la crianza que permean buena parte del contenido etnográfico del libro conseguen reflejar plenamente las distinciones que los rituales, según la introducción del editor, se ocuparían de comentar (sea entre humano y animal o entre colectivo e individuo). Creo que los ejemplos de la compilación de Rivera Andía, en la voz de sus diferentes autores, contribuyen así a repensar esta " comunicación entre especies ", a la cual apuntaba otro libro inspirador (Arnold y Yapita 1998). Nos ayudan a imaginar formas posibles de comprender (y tal vez participar de) aquella conversación que nunca abandonó los cerros.

\section{BIBLIOGRAFÍA}

\section{ARNOLD Denise y Juan de Dios YAPITA}

1998, Río de vellón, río de canto. Cantar a los animales, una poética andina de la creación, Facultad de Humanidades y Ciencias de la Educación, Carrera de Literatura, Universidad Mayor de San Andrés, La Paz.

MARTINEZ Gabriel

1989, « El sistema de los uywiris en Isluga », in Gabriel Martinez, Espacio y Pensamiento. I, Andes Meridionales, Hisbol, La Paz, p. 13-107.

RICARD LANATA Xavier

2007, Ladrones de sombra. El universo religioso de los pastores del Ausangate (Andes surperuanos), Instituto Francés de estudios andinos/Centro de estudios regionales andinos Bartolomé de Las Casas, Lima/Cuzco.

\section{NOTAS}

1. Esto podría incluso confrontarse con las versiones míticas sobre el origen de los animales y con otras etnografías sobre el tema. Ver al respecto el trabajo de Ricard Lanata (2007) sobre los pastores quechuas del Ausangate, región del Cuzco, particularmente la relación " autonomía-dependencia » entre los humanos y los apus o cerros (que son también seres vivos con los cuales se establecen relaciones). 


\section{AUTORES}

\section{FRANCISCO PAZZARELLI}

Instituto de Antropología de Córdoba-Conicet, Facultad de Filosofía y Humanidades, Universidad Nacional de Córdoba, Argentina 